\title{
Relationship among S-N curves corresponding to different mean stresses or stress ratios"
}

\author{
Shan-qin $\mathrm{HOU}^{1,2}$, Jin-quan $\mathrm{XU}^{\dagger \$ 1}$ \\ ( ${ }^{1}$ School of Naval Architecture, Ocean and Civil Engineering, Shanghai Jiao Tong University, Shanghai 200240, China) \\ ( ${ }^{2}$ School of Science, Shan Dong Jiaotong University, Jinan 250357, China) \\ ${ }^{\dagger}$ E-mail: jqxu@sjtu.edu.cn
}

Received Oct. 22, 2014; Revision accepted Mar. 1, 2015; Crosschecked Oct. 16, 2015

\begin{abstract}
It is well known that the mean stress or stress ratio of fatigue loadings has a strong effect on the shape of S-N curves. An understanding of the relationships among S-N curves corresponding to different mean stresses or stress ratios would be very useful in engineering applications. In this study, based on continuum damage mechanics, a mathematical expression of an S-N curve is deduced from a new damage evolution law. This mathematical expression can well represent the whole S-N curve, not only the linear part in bi-logarithmic diagrams, but also the transitional part near the fatigue limit. The effect of mean stress on an S-N curve is represented by two state parameters. The relationships between these state parameters and the mean stress are proposed and examined. By using these relationships, the concepts of equivalent symmetric amplitude and equivalent symmetric cycles are introduced. We have found that all S-N curves under non-symmetric states can be rearranged into the same curve as that of symmetric fatigue by adopting these equivalent parameters.
\end{abstract}

Key words: Damage mechanics, S-N curve, Evolution law, Equivalent method, Fatigue limit doi: $10.1631 /$ jzus.A1400321

Document code: A

CLC number: 0346.2

\section{Introduction}

Due to its importance in engineering, many studies on fatigue using various approaches can be found in previous studies (Mutoh and $\mathrm{Xu}, 2003$; Lee et al., 2012; Alexopoulos et al., 2013; Huang and Xu, 2013; El Sawi et al., 2014; Humayun Kabir et al., 2014). From the point of view of application, the S-N curve method is still the approach most widely used to estimate fatigue life. An S-N curve is a plot of stress vs. the number of cycles to failure. Many empirical fatigue life evaluation laws have been proposed (Stephens and Fuchs, 2001; Liu and Zhang,

\footnotetext{
$\ddagger$ Corresponding author

* Project supported by the National Natural Science Foundation of China (No. 10772116)

(D) ORCID: Shan-qin HOU, http://orcid.org/0000-0002-8293-6894

(C) Zhejiang University and Springer-Verlag Berlin Heidelberg 2015
}

2012; Avanzini et al., 2013; Han et al., 2014; Kravchenko et al., 2014). However, it is well known that the mean stress or stress ratio of fatigue loadings has a strong effect on the shape of S-N curves. This effect means that an empirical life evaluation law usually is applicable only with strict constraints on the stress state under which the law has been fitted. There have been many studies on establishing fatigue theory (Verreman and Guo, 2007; Deng et al., 2014; Peng et al., 2014; Soppa et al., 2014), mainly by means of fracture mechanics and continuum damage mechanics. Ayoub et al. (2011) proposed a continuum damage model for high-cycle fatigue life prediction. Abdul-Baqi et al. (2005) used a cohesive zone approach to develop a fatigue damage model. Cusumano and Chatterjee (2000) deduced a dynamics formula for fatigue damage evolution. Milašinović (2003) proposed a model of fatigue behavior named the rheological-dynamical analogy for inelastic 
materials and structures. Chamos et al. (2010) found high stress sensitivity at high applied stresses due to very early crack initiation. Jabbado and Maitournam (2008) proposed a fatigue life model with six parameters based on a multi-scale approach and Morel (2001) used the accumulated plastic meso-strain to predict fatigue life.

Since the S-N curve is dependent on the mean stress or stress ratio, it would be valuable and meaningful to clarify the relationship among S-N curves corresponding to different cyclic stress states for practical fatigue life estimations. To investigate this relationship, a reasonable mathematical expression of an $\mathrm{S}-\mathrm{N}$ curve is necessary, containing parameters to represent the effect of mean stress, and able to represent the whole S-N curve. The approach of continuum damage mechanics was adopted in this study to obtain a mathematical expression of an S-N curve. Based on the mathematical expression and experimental results, the relationship among S-N curves corresponding to different mean stresses or stress ratios was studied.

\section{Fatigue damage evolution and a mathe- matical expression of an S-N curve}

Considering the fatigue loading as

$$
\sigma=\sigma_{\mathrm{m}}+\sigma_{\mathrm{a}} \sin (\omega t)=\sigma_{\mathrm{m}}+\sigma_{\mathrm{t}}
$$

where $\sigma_{\mathrm{m}}$ is the cyclic mean stress, $\sigma_{\mathrm{a}}$ is the cyclic stress amplitude, $\omega$ is the angular velocity, $t$ is the time, and $\sigma_{\mathrm{t}}$ is the cyclic part of stress (stress can be composed of several sinusoidal functions, but here we consider only the most simple case for simplicity).

The best way to establish a fatigue damage evolution law is to deduce it from the fatigue mechanism. However, it is difficult to obtain a theoretical evolution law since fatigue mechanisms are not very clear. The well-known Kachanov's damage law (Kachanov, 1986) is

$$
\frac{\mathrm{d} D}{\mathrm{~d} t}=c\left(\frac{\sigma}{1-D}\right)^{m}
$$

where $c$ is a proportional coefficient, $D$ is the damage variable, and $m$ is a material constant. According to this law, the following properties and modifications have been considered. When $\sigma_{\mathrm{t}}$ is smaller than the fatigue limit of the material, damage accumulation can be neglected. For static loadings, the damage accumulation should be negligible, so the term $\dot{\sigma}_{\mathrm{t}}$ has been introduced. By adopting these modifications, we proposed to establish a fatigue damage evolution law empirically. The validity of this law should be tested by experiments.

$$
\begin{gathered}
\frac{\mathrm{d} D}{\mathrm{~d} t}=c_{\mathrm{m}} \frac{\dot{\sigma}_{\mathrm{t}} \sigma_{\mathrm{t}}^{\beta}}{(1-D)^{\beta+1}} H\left(\sigma_{\mathrm{t}}\right), \\
H\left(\sigma_{\mathrm{t}}\right)= \begin{cases}1-\left(\frac{(1-D) \sigma_{\mathrm{ffm}}}{\left|\sigma_{\mathrm{t}}\right|}\right)^{\gamma}, & \frac{\left|\sigma_{\mathrm{t}}\right|}{1-D}>\sigma_{\mathrm{fm}}, \\
0, & \frac{\left|\sigma_{\mathrm{t}}\right|}{1-D} \leq \sigma_{\mathrm{fm}} .\end{cases}
\end{gathered}
$$

Here, $\dot{\sigma}_{\mathrm{t}}=\mathrm{d} \sigma_{\mathrm{t}} / \mathrm{d} t$, so fixed loadings would not lead to damage evolution. $\beta$ and $\gamma$ should be material constants since they determine the evolution function which corresponds to the intrinsic damage accumulation style. $\sigma_{\mathrm{fm}}$ is the fatigue limit and $c_{\mathrm{m}}$ is a proportional coefficient of damage. Both $\sigma_{\mathrm{fm}}$ and $c_{\mathrm{m}}$ should be dependent on mean stress, since the variable $\sigma_{\mathrm{t}}$ in Eq. (2) is only the cyclic part of stress, so the effect of mean stress must be included in the coefficients. We call $\sigma_{\mathrm{fm}}$ and $c_{\mathrm{m}}$ 'state properties' for convenience, since they are not fixed constants. Rewriting Eq. (2) by cycles instead of time, and using Eq. (1) gives:

$$
\begin{aligned}
& \frac{\mathrm{d} D}{\mathrm{~d} N}=c_{\mathrm{m}}\left(\frac{\sigma_{\mathrm{a}}}{1-D}\right)^{\beta+1} \int_{0}^{2 \pi} H\left(\sigma_{\mathrm{t}}\right)|\sin \theta|^{\beta}|\cos \theta| \mathrm{d} \theta \\
&=c_{\mathrm{m}}\left(\frac{\sigma_{\mathrm{a}}}{1-D}\right)^{\beta+1} t_{1}, \\
& t_{1}=\int_{0}^{2 \pi}|\sin \theta|^{\beta}|\cos \theta| H\left(\sigma_{\mathrm{t}}\right) \mathrm{d} \theta \\
&=2 \int_{\theta_{1}}^{\pi-\theta_{1}}\left(1-\left(\frac{1-D}{\sigma_{\mathrm{a}}|\sin \theta|} \sigma_{\mathrm{ffm}}\right)^{\gamma}\right)|\sin \theta|^{\beta}|\cos \theta| \mathrm{d} \theta, \\
& \theta_{1}=\arcsin \frac{\sigma_{\mathrm{fm}}(1-D)}{\sigma_{\mathrm{a}}} .
\end{aligned}
$$

By integrating Eq. (3a), denoting the initial and critical damages by $D_{0}$ and $D_{\mathrm{C}}$, respectively, the mathematical expression of the S-N curve can be obtained as 


$$
\begin{gathered}
\sigma_{\mathrm{a}}^{\beta+1} N_{\mathrm{f}}=\int_{D_{0}}^{D_{\mathrm{C}}} \frac{(1-D)^{\beta+1} \mathrm{~d} D}{c_{\mathrm{m}} t_{1}}=C_{\mathrm{m}} I\left(\sigma_{\mathrm{a}}\right), \\
I\left(\sigma_{\mathrm{a}}\right)=\int_{D_{0}}^{D_{\mathrm{C}}} \frac{(1-D)^{\beta+1} \mathrm{~d} D}{t_{1}}
\end{gathered}
$$

where $C_{\mathrm{m}}=1 / c_{\mathrm{m}}$ is the proportional coefficient of life and $N_{\mathrm{f}}$ is the fatigue life. $t_{1}$ and $I\left(\sigma_{\mathrm{a}}\right)$ can be calculated using Gauss's numerical integral procedures. Introducing the transformations

$$
\theta=\left(\frac{\pi}{2}-\theta_{1}\right) \zeta+\frac{\pi}{2}
$$

to Eq. (3b), and

$$
D=0.5\left(D_{\mathrm{C}}-D_{0}\right) \xi+0.5\left(D_{\mathrm{C}}+D_{0}\right)
$$

to Eq. (4b), the standardized Gauss numerical integral forms can be obtained:

$$
\begin{aligned}
& t_{1}=2\left(\frac{\pi}{2}-\theta_{1}\right) \sum_{i=1}^{M} w_{i}\left[1-\left(\frac{1-D}{\sigma_{\mathrm{a}}\left|\cos \left(\frac{\pi}{2}-\theta_{1}\right) \zeta_{i}\right|} \sigma_{\mathrm{r}}\right)^{\gamma}\right] \\
& \cdot\left|\cos \left(\frac{\pi}{2}-\theta_{1}\right) \zeta_{i}\right|^{\beta}\left|\sin \left(\frac{\pi}{2}-\theta_{1}\right) \zeta_{i}\right|, \\
& I\left(\sigma_{\mathrm{a}}\right)=0.5\left(D_{\mathrm{C}}-D_{0}\right) \\
& \cdot \sum_{j=1}^{M} \frac{\left[1-0.5\left(D_{\mathrm{C}}-D_{0}\right) \xi_{j}-0.5\left(D_{\mathrm{C}}+D_{0}\right)\right]^{\beta+1} w_{j}}{t_{1 j}}
\end{aligned}
$$

where $M$ is the number of Gauss integral points, and $\zeta_{i}$, $\xi_{j}$ and $w_{i}, w_{j}$ are the Gauss point values and weight coefficients, respectively.

Comparing Eq. (4a) with the traditional empirical life evaluation formula $\sigma_{\mathrm{a}}^{m} N_{\mathrm{f}}=C$, it can be seen that the difference is due only to the new term $I\left(\sigma_{\mathrm{a}}\right)$. Fig. 1 shows an example of the variation in $I\left(\sigma_{\mathrm{a}}\right)$ with stress amplitude. $I\left(\sigma_{\mathrm{a}}\right)$ becomes near to a constant value with the increase in stress amplitude. This means that Eq. (4a) agrees with the traditional empirical life formula for relatively high stress amplitudes. However, for relatively low stress amplitudes, especially for those near the fatigue limit $\left(\sigma_{\mathrm{a}} / \sigma_{\mathrm{fm}} \rightarrow 1\right)$, $I\left(\sigma_{\mathrm{a}}\right)$ varies dramatically, so the simple traditional empirical life formula cannot be applied again.

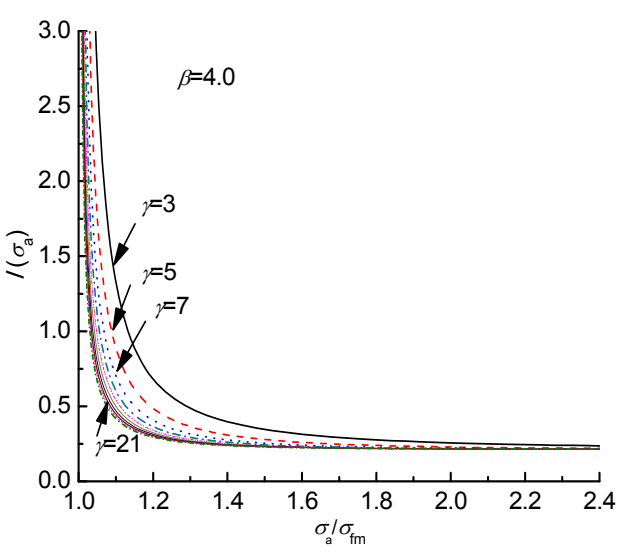

Fig. 1 An example of the variation in $I\left(\sigma_{\mathrm{a}}\right)$

In Eq. (4), there are two material constants $\beta, \gamma$, two state properties $C_{\mathrm{m}}, \sigma_{\mathrm{fm}}$, and two damage parameters $D_{0}, D_{\mathrm{C}}$. In relation to the initial damage, one can always assume that $D_{0} \approx 0$ if the material has not been subjected to any cyclic loadings for metals. However, for materials such as ceramics, and glass fibers and even for metals which have been subjected to cyclic loadings, the initial damage may be quite large and should be determined before fatigue life evaluation. In relation to the critical damage $D_{\mathrm{C}}$, Fig. 2 illustrates its effect on fatigue life according to Eq. (4). S-N curves corresponding to different $D_{\mathrm{C}}$ values coincide when $D_{\mathrm{C}} \geq 0.5$. This is reasonable because damage accumulation becomes very rapid after $D>0.5$, and the corresponding life can be neglected compared with that for accumulation up to $D=0.5$. Therefore, one can always set $D_{\mathrm{C}}=0.5$ in applications. Fig. 3 shows the effects of $\gamma$ on the S-N curve. $\beta$ corresponds to the slope of the linear part, while $\gamma$ affects the shape of the transitional part of the S-N curve. The smaller the value of $\gamma$ is, the larger the transitional region becomes, and the flatter the transition curve becomes. These tendencies may be very useful in the determination of a material's constants $\beta, \gamma$ from experimental results.

\section{Experimental examination of the fatigue life evaluation formula}

Many experimental estimates of fatigue life have been published. The test results used below are all referenced from Gao (1981)'s handbook. Fig. 4 shows comparisons of Eq. (4) with test results for fixed stress ratio conditions, where S-N curves are 
calculated from Eq. (4) by assuming $C_{\mathrm{m}}, \sigma_{\mathrm{fm}}$ are constants for a specified stress ratio (denoted by $C_{r}, \sigma_{r}$, where $r$ denotes the stress ratio). However, for the cases of $r \neq-1, C_{r}$ and $\sigma_{r}$ may not be constants since the corresponding mean stress varies with stress amplitude (discussed later). Note that $C_{\mathrm{m}}$ has a unit of

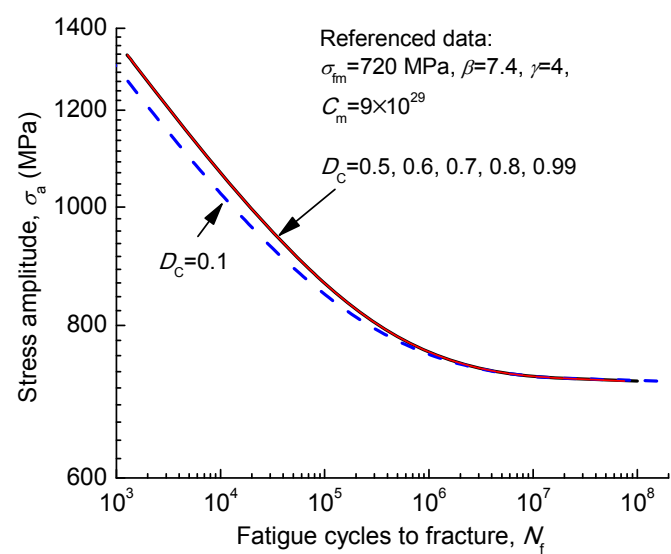

Fig. 2 Effect of $D_{C}$ on an S-N curve

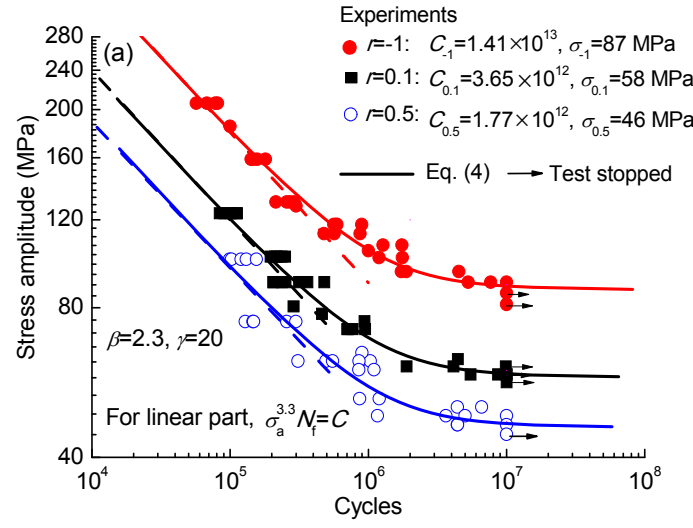

$(\mathrm{MPa})^{\beta+1}$ cycle, but it is omitted below for simplicity. Fig. 5 shows comparisons for fixed mean stress conditions, where S-N curves are calculated from Eq. (4) by considering that $C_{\mathrm{m}}, \sigma_{\mathrm{fm}}$ are constants for a specified mean stress. Figs. 4 and 5 show that the S-N curves of Eq. (4) for different stress ratios and mean

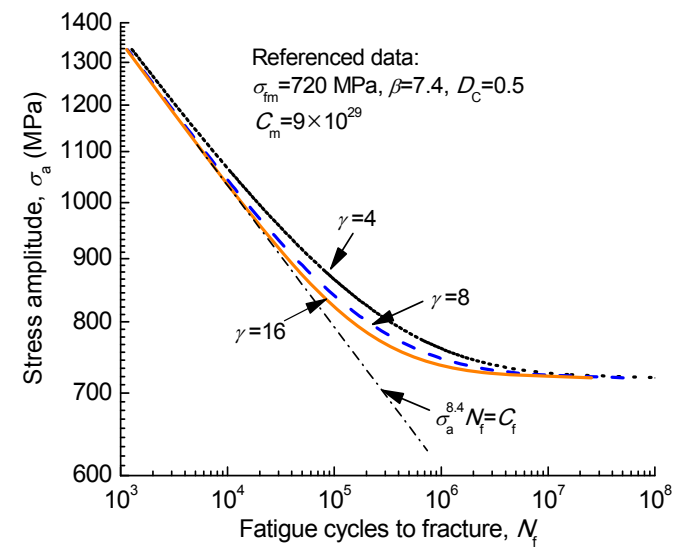

Fig. 3 Effect of $\gamma$ on an S-N curve

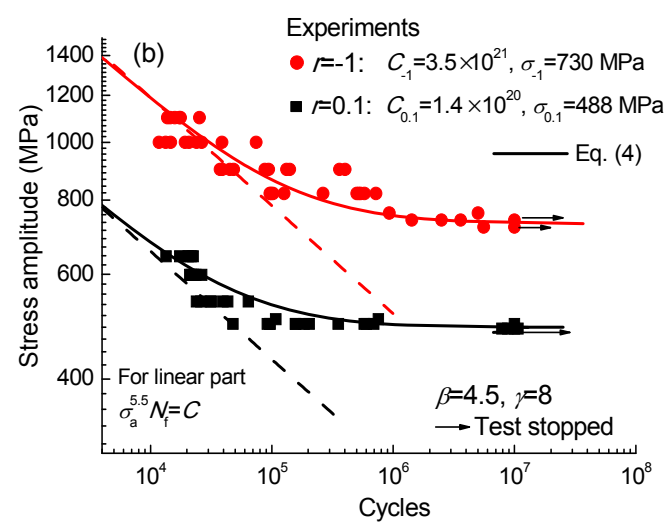

Fig. 4 Comparisons for fixed stress ratio cases

(a) Over-aged high strength aluminum alloy LC9; (b) GC-4 steel
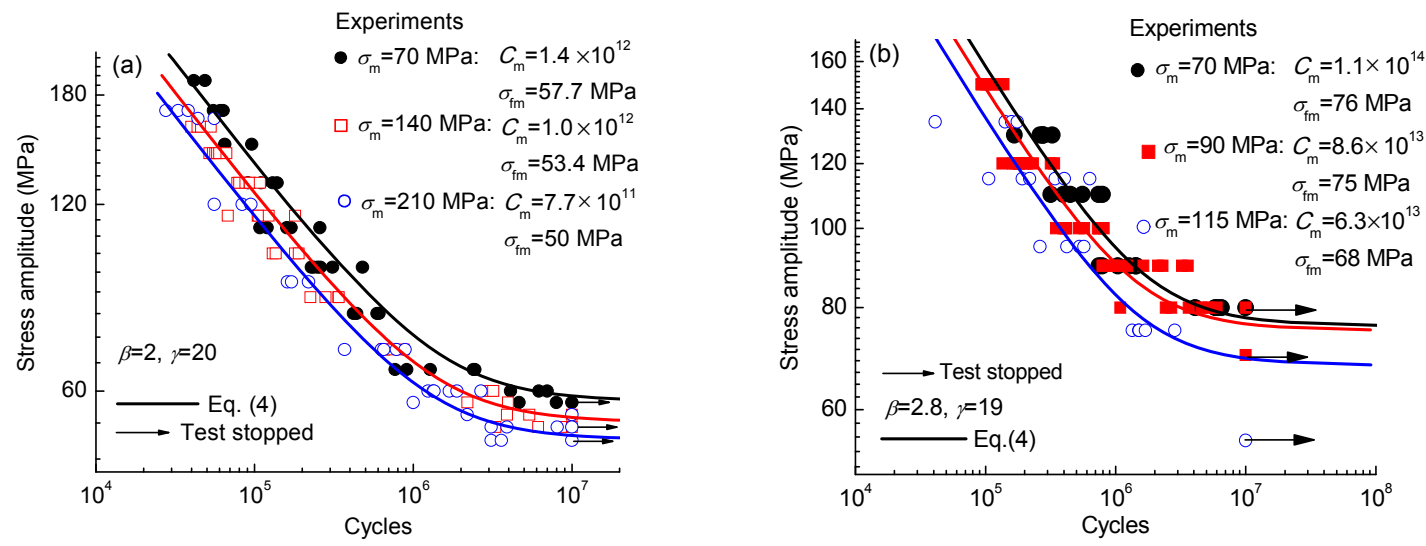

Fig. 5 Comparisons for fixed mean stress cases

(a) High strength aluminum alloy LC4; (b) Aluminum alloy LY12CZ* 
stresses can well describe the corresponding experimental results, not only for the linear part, but also for the transitional part. From these comparisons, it can be considered that the assumption of Eq. (2) about damage accumulation is valid.

In the above examinations, state parameters $C_{\mathrm{m}}$, $\sigma_{\mathrm{fm}}$ were obtained by fitting test results. However, they are a material's properties, not test parameters. If the relationship between these state parameters and mean stress can be pre-determined, $C_{\mathrm{m}}, \sigma_{\mathrm{fm}}$ can be simply calculated, and a fitting process is no longer necessary.

\section{Results}

\subsection{Relationship between fatigue limit and mean stress}

There are some classic but very rough relationships between fatigue limit and mean stress, such as Goodman (1899)'s linear relationship and Gerber (1874)'s elliptical relationship. However, in Eq. (4), we need a quantitative value of the fatigue limit corresponding to a specified mean stress. We found that the following formula can quantitatively describe the relationship between the fatigue limit $\sigma_{\mathrm{fm}}$ and mean stress $\sigma_{\mathrm{m}}$ :

$$
\begin{gathered}
\sigma_{\mathrm{fm}}=\frac{S_{\mathrm{m}} \sigma_{-1}-\sigma_{\mathrm{m}}+\sqrt{\left[S_{\mathrm{m}} \sigma_{-1}-\sigma_{\mathrm{m}}\right]^{2}+4 \eta S_{\mathrm{m}} \sigma_{-1} \sigma_{\mathrm{m}}}}{2}, \\
S_{\mathrm{m}}=1-\left(\frac{\sigma_{\mathrm{m}}}{\sigma_{\mathrm{b}}}\right)^{\alpha},
\end{gathered}
$$

where $\sigma_{\mathrm{b}}$ is the tensile strength of the material, $\eta$ and $\alpha$ are material constants, and $\sigma_{-1}$ is the fatigue limit for symmetric fatigue. Eq. (8) shows that three fatigue constants, together with the tensile strength, are necessary to determine the fatigue limit for arbitrary mean stress quantitatively. Fig. 6 shows comparisons of experimental results with Eq. (8). Eq. (8) is accurate enough to describe the fatigue limit for any mean stress. Note that the fatigue limit may not always correspond to $10^{7}$ cycles. Eq. (8) has been examined for many materials and found to be valid for all. The reason is simple: the function shown in Eq. (8) can express a very complicated curve within the range of $\sigma_{\mathrm{m}}=0$ to $\sigma_{\mathrm{m}}=\sigma_{\mathrm{b}}$ by selecting proper constants $\eta, \alpha$. Therefore, Eq. (8) mathematically describes the ma- terial's intrinsic relationship, though it is only an empirical relationship.
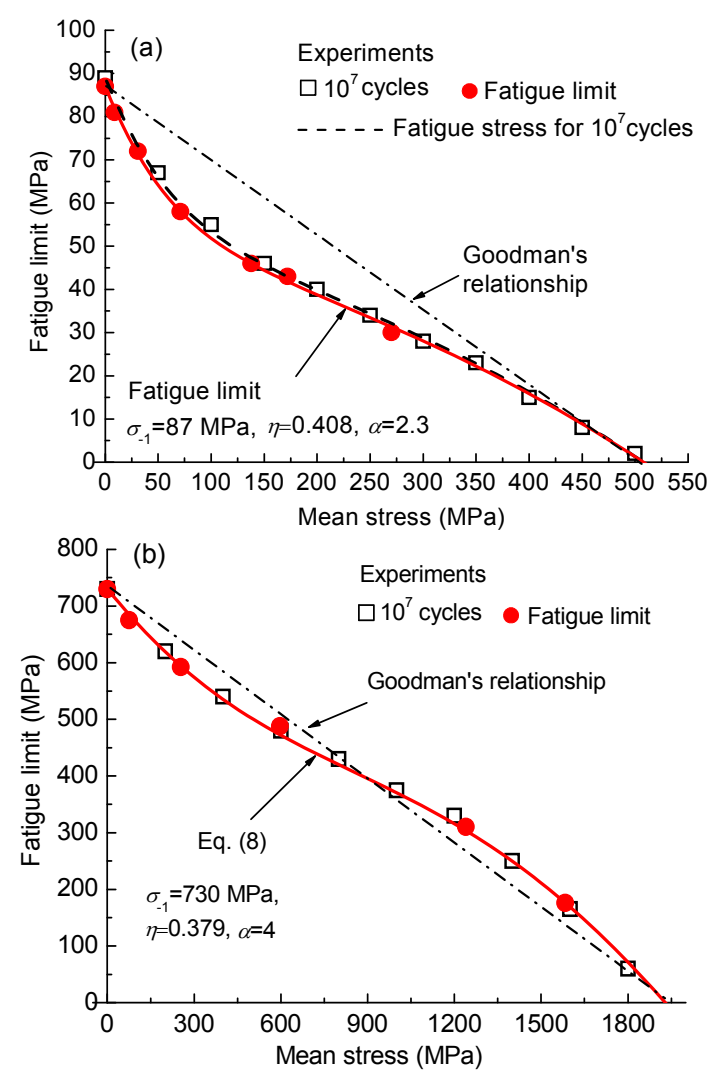

Fig. 6 Fatigue limit for various mean stresses (a) LC9; (b) GC-4 steel

\subsection{Relationship between $C_{\mathrm{m}}$ and $\sigma_{\mathrm{fm}}$}

From the experimental data under fixed mean stress conditions, we found that there is a good linear relationship between $\log C_{\mathrm{m}}$ and $\log \sigma_{\mathrm{fm}}$ (Fig. 7). Thus, simply, we obtain:

$$
C_{\mathrm{m}}=C_{0} \sigma_{\mathrm{fm}}^{\kappa^{\prime}}=C_{-1}\left(\frac{\sigma_{\mathrm{fm}}}{\sigma_{-1}}\right)^{\kappa^{\prime}}
$$

where $\kappa^{\prime}$ is a material constant, and $C_{-1}$ is the proportional coefficient. $\sigma_{\mathrm{fm}}$ is the fatigue limit corresponding to the mean stress $\sigma_{\mathrm{m}}$ (Eq. (8)). It is important to note that the state property $C_{\mathrm{m}}$ is dependent on the fatigue limit $\sigma_{\mathrm{fm}}$ instead of the mean stress $\sigma_{\mathrm{m}}$ directly. This means that to evaluate fatigue life quantitatively, the fatigue limit corresponding to the current mean stress is required. Eq. (9) is also a mathematical description of a material's intrinsic behavior, though it too is only an empirical description. 


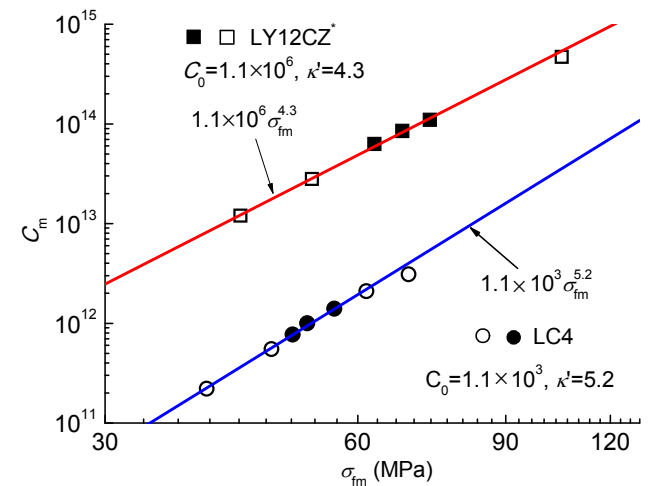

Fig. 7 Relationship between $\log C_{\mathrm{m}}$ and $\log \sigma_{\mathrm{fm}}$

\subsection{Relationship among S-N curves}

Using Eqs. (8) and (9), the fatigue life evaluation formula Eq. (4) can be generalized for any cyclic loadings as

$$
\sigma_{\mathrm{a}}^{\beta+1} N_{\mathrm{f}}=C_{-1}\left(\frac{\sigma_{\mathrm{fm}}}{\sigma_{-1}}\right)^{\kappa^{\prime}} I\left(\sigma_{\mathrm{a}}\right)
$$

Introducing the concept of equivalent symmetric stress amplitude and equivalent symmetric cycles as

$$
\begin{gathered}
\sigma_{\mathrm{ae}}=\frac{\sigma_{-1}}{\sigma_{\mathrm{fm}}} \sigma_{\mathrm{a}}, \\
N_{\mathrm{ef}}=\left(\frac{\sigma_{-1}}{\sigma_{\mathrm{fm}}}\right)^{\kappa^{\prime}-\beta-1} N_{\mathrm{f}}=\left(\frac{\sigma_{-1}}{\sigma_{\mathrm{fm}}}\right)^{\kappa} N_{\mathrm{f}}, \kappa=\kappa^{\prime}-\beta-1 .
\end{gathered}
$$

Eq. (10) can be rearranged into a unified form

$$
\sigma_{\mathrm{ae}}^{\beta+1} N_{\mathrm{ef}}=C_{-1} I\left(\sigma_{\mathrm{ae}}\right)
$$

where

$$
\begin{gathered}
I\left(\sigma_{\text {ae }}\right)=I\left(\sigma_{\mathrm{a}}\right)=\int_{D_{0}}^{D_{\mathrm{c}}} \frac{(1-D)^{\beta+1} \mathrm{~d} D}{t_{1}}, \\
t_{1}=\int_{0}^{2 \pi}|\sin \theta|^{\beta}|\cos \theta| H\left(\sigma_{\mathrm{ac}}\right) \mathrm{d} \theta, \\
H\left(\sigma_{\text {ae }}\right)=H\left(\sigma_{\mathrm{a}}\right) \\
= \begin{cases}1-\left(\frac{(1-D) \sigma_{-1}}{\sigma_{\text {ae }}|\sin \theta|}\right)^{\gamma}, & \frac{\sigma_{\text {ae }}|\sin \theta|}{1-D}>\sigma_{-1}, \\
0, & \frac{\sigma_{\text {ae }}|\sin \theta|}{1-D} \leq \sigma_{-1} .\end{cases}
\end{gathered}
$$

Eq. (12) means that there is only one intrinsic S-N curve for a material. That is, by adopting the equivalent symmetric stress amplitude and equivalent symmetric cycles, all experimental data for any cyclic loadings must locate at the same S-N curve of symmetric fatigue. Figs. 8 and 9 show examples of experimental results obtained by fixed stress ratio and fixed mean stress tests. No matter what the cyclic condition, experimental results locate on the same symmetric cyclic S-N curve very well.

\section{Discussion}

Traditionally, a fatigue life test is usually carried out under fixed stress ratio conditions. In this case, the mean stress varies with the amplitude under nonsymmetric cyclic loadings as $\sigma_{\mathrm{m}}=(1+r) \sigma_{\mathrm{a}} /(1-r)$, so both the proportional coefficient and fatigue limit vary with the amplitude. The so called fatigue limit $\sigma_{r}$ at a specified stress ratio corresponds to the special mean stress $\sigma_{\mathrm{m} 0}=(1+r) \sigma_{r} /(1-r)$ only. This means that the experimental S-N curve corresponding to a specified stress ratio $(r \neq-1)$ contains not only the effect of stress amplitude, but also the effect of variation in state parameters. Therefore, the experimental S-N curves corresponding to different stress ratios can be fitted only separately. Not only the fitting parameters, but also the fitting function may be different. So it is difficult to find directly the relationship among experimental S-N curves corresponding to various stress ratios. The mathematical expression of an S-N curve in this study was deduced from the damage evolution law, without any constraint on the cyclic stress state. Thus, experimental results obtained from a fixed stress ratio can also be rearranged into a unified form (Fig. 8). However, after such a rearrangement, the S-N curve does not correspond to a specified non-symmetric stress ratio again, but corresponds to the intrinsic S-N curve of the material.

To apply the unified life evaluation formula Eq. (12), a material's fatigue properties should be pre-determined. In other words, fatigue experiments are required only to determine a material's fatigue properties by this formula, and it is no longer necessary to determine experimental S-N curves for different mean stresses or stress ratios as a database. Obviously, this can greatly reduce the number of fatigue tests in application. There are seven material 
fatigue property constants in the unified fatigue life formula. Four of them $\left(\sigma_{-1}, C_{-1}, \beta\right.$, and $\left.\gamma\right)$ can be determined completely by symmetric cyclic fatigue tests $(r=-1) . \eta$ and $\alpha$ can be determined by non-zero mean stress tests, but only those tests with an amplitude near to the corresponding fatigue limit are necessary, since $\eta$ and $\alpha$ are parameters related only to the fatigue limit. To determine the coefficient $\kappa^{\prime}$ or $\kappa$, besides $C_{-1}$, only one $C_{\mathrm{m}}$ value corresponding to a non-zero mean stress is necessary. To determine $C_{\mathrm{m}}$ for a specified mean stress, only some tests with relatively high amplitudes are necessary due to the linearity of the S-N curve.

Table 1 shows the fatigue property constants for some metals. With these material's constants, the fatigue life for any cyclic stress state can be estimated by Eq. (12), and no additional tests with a specified mean stress or stress ratio are required.
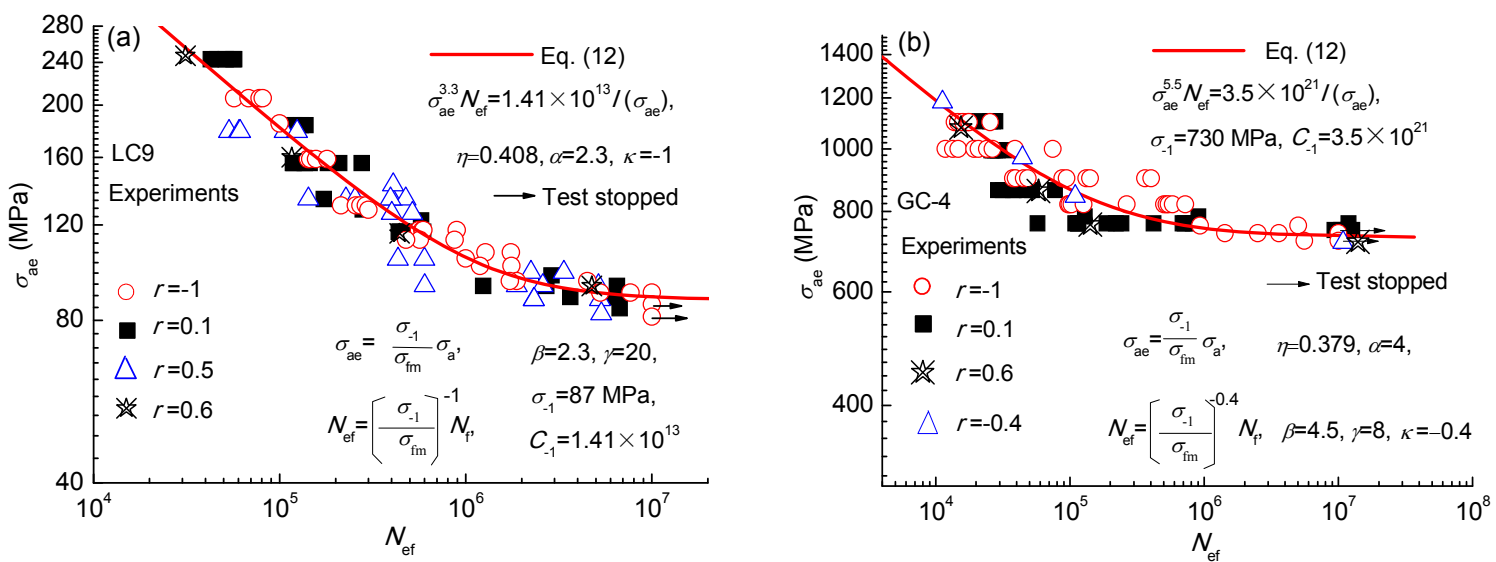

Fig. 8 Unified evaluation of fatigue life under fixed stress ratio conditions (a) LC9; (b) GC-4 steel
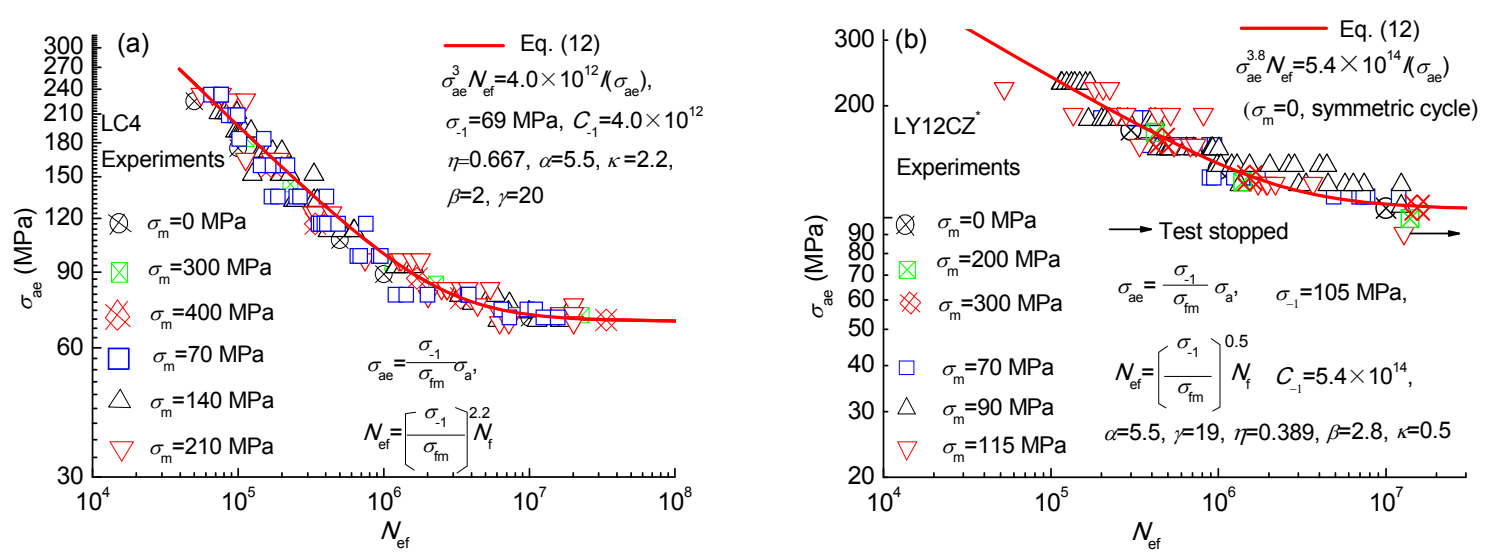

Fig. 9 Unified evaluation of fatigue life under fixed mean stress conditions (a) LC4; (b) LY12CZ*

Table 1 Fatigue constants of some metals

\begin{tabular}{lccccccrc}
\hline \multicolumn{1}{c}{ Material } & $\sigma_{-1}(\mathrm{MPa})$ & $C_{-1}$ & $\beta$ & $\gamma$ & $\eta$ & $\alpha$ & $\kappa=\kappa^{\prime}-\beta-1$ & $\sigma_{\mathrm{b}}(\mathrm{MPa})$ \\
\hline LC9 & 87 & $1.41 \times 10^{13}$ & 2.3 & 20 & 0.408 & 2.3 & -1.0 & 508 \\
LY12B & 120 & $1.05 \times 10^{22}$ & 6.0 & 18 & 0.667 & 3.5 & 1.5 & 464 \\
LY12CZ & 81 & $3.90 \times 10^{13}$ & 2.5 & 19 & 0.527 & 7.5 & -0.6 & 466 \\
LY12CZ & 105 & $5.40 \times 10^{14}$ & 2.8 & 19 & 0.389 & 5.5 & 0.5 & 460 \\
LC4 & 69 & $0.40 \times 10^{13}$ & 2.0 & 20 & 0.667 & 5.5 & 2.2 & 549 \\
GC-4 steel & 730 & $3.50 \times 10^{21}$ & 4.5 & 8 & 0.379 & 4.0 & -0.4 & 2010 \\
\hline
\end{tabular}

Note: the dimension of $C_{-1}$ is $(\mathrm{MPa})^{\beta+1}$ cycle; the former five materials are aluminum alloys; $\mathrm{LY} 12 \mathrm{CZ}^{*}$ and $\mathrm{LY} 12 \mathrm{CZ}$ are different materials due to their different composition (different manufacturers) 


\section{Conclusions}

The main conclusions are as follows:

1. A damage evolution law which can describe the whole S-N curve has been proposed, and a fatigue life evaluation formula deduced.

2. The empirical quantitative relationship between the fatigue limit and mean stress has been proposed and examined.

3. The empirical relationship between the proportional coefficient and the fatigue limit has been proposed and examined.

4. The concepts of equivalent symmetric stress amplitude and equivalent symmetric cycles have been proposed. With the use of these concepts, the fatigue life under non-zero mean stress state can be evaluated in a way equivalent to that of symmetric fatigue.

5. There is only one intrinsic S-N curve for a material from which all others under non-zero mean stress can be deduced.

6. There are seven material fatigue property constants. To determine them, besides the symmetric cyclic fatigue tests, only a few non-zero mean stress tests are necessary.

\section{References}

Abdul-Baqi, A., Schreurs, P.J.G., Geers, M.G.D., 2005. Fatigue damage modeling in solder interconnects using a cohesive zone approach. International Journal of Solids and Structures, 42(3-4):927-942. [doi:10.1016/j. ijsolstr.2004.07.026]

Alexopoulos, N.D., Migklis, E., Stylianos, A., et al., 2013. Fatigue behavior of the aeronautical Al-Li (2198) aluminum alloy under constant amplitude loading. International Journal of Fatigue, 56:95-105. [doi:10.1016/j. ijfatigue.2013.07.009]

Avanzini, A., Donzella, G., Gallina, D., et al., 2013. Fatigue behavior and cyclic damage of peek short fiber reinforced composites. Composites Part B: Engineering, 45(1):397406. [doi:10.1016/j.compositesb.2012.06.008]

Ayoub, G., Abdelaziz, M.N., Zairi, F., et al., 2011. A continuum damage model for the high cycle fatigue life prediction of styrene-butadiene rubber under multiaxial loading. International Journal of Solids and Structures, 48(18):2458-2466. [doi:10.1016/j.ijsolstr.2011.04.003]

Chamos, A.N., Charitidis, C.A., Skarmoutsou, A., et al., 2010. An investigation on the high stress sensitivity of fatigue life of rolled AZ31 magnesium alloy under constant amplitude fatigue loading. Fatigue \& Fracture of Engineering Materials \& Structures, 33(4):252-265. [doi:10. 1111/j.1460-2695.2009.01434.x]

Cusumano, J.P., Chatterjee, A., 2000. Steps towards a qualitative dynamics of damage evolution. International
Journal of Solids and Structures, 37(44):6397-6417. [doi:10.1016/S0020-7683(99)00042-6]

Deng, G.J., Tu, S.T., Wang, Q.Q., et al., 2014. Small fatigue crack growth mechanisms of 304 stainless steel under different stress levels. International Journal of Fatigue, 64:14-21. [doi:10.1016/j.ijfatigue.2014.01.027]

El Sawi, I., Fawaz, Z., Zitoune, R., et al., 2014. An investigation of the damage mechanisms and fatigue life diagrams of flax fiber-reinforced polymer laminates. Journal of Materials Science, 49(5):2338-2346. [doi:10. 1007/s10853-013-7934-0]

Gao, Z.T., 1981. A Handbook on Fatigue Properties of Aeronautical Material. Beijing Material Research Institute, Beijing, China, p.45-223 (in Chinese).

Gerber, H., 1874. Bestimung der zulassigen spannungen in Eisen-konstructionzen. Zeischrift des Bayerischen Architeckten und Ingenieur-vereins, 6:101-110 (in German).

Goodman, J., 1899. Mechanics Applied to Engineering. Longman, London.

Han, Z.Y., Huang, X.G., Cao, Y.G., et al., 2014. A nonlinear cumulative evolution model for corrosion fatigue damage. Journal of Zhejiang University-SCIENCE A (Applied Physics \& Engineering), 15(6):447-453. [doi:10.1631/ jzus.A1300362]

Huang, X.G., Xu, J.Q., 2013. 3D analysis for pit evolution and pit-to-crack transition during corrosion fatigue. Journal of Zhejiang University-SCIENCE A (Applied Physics \& Engineering), 14(4):292-299. [doi:10.1631/jzus. A1200273]

Humayun Kabir, S.M., Yeo, T.I., 2014. Evaluation of an energy-based fatigue approach considering mean stress effects. Journal of Mechanical Science and Technology, 28(4):1265-1275. [doi:10.1007/s12206-013-1155-y]

Jabbado, M., Maitournam, M.H., 2008. A high-cycle fatigue life model for variable amplitude multiaxial loading. $\mathrm{Fa}$ tigue \& Fracture of Engineering Materials \& Structures, 31(1):67-75. [doi:10.1111/j.1460-2695.2007.01201.x]

Kachanov, L.M., 1986. Introduction to Continuum Damage Mechanics. Martinus Nijhoff, Dordrecht, the Netherlands, p.138.

Kravchenko, S.G., Kravchenko, O.G., Sun, C.T., 2014. A two-parameter fracture mechanics model for fatigue crack growth in brittle materials. Engineering Fracture Mechanics, 119:132-147. [doi:10.1016/j.engfracmech. 2014.02.018]

Lee, Y.L., Barkey, M.E., Kang, H.T., 2012. Metal Fatigue Analysis Handbook. Elsevier, Oxford, p.383-460.

Liu, J., Zhang, F., 2012. Fatigue life prediction of composite laminate. Advanced Materials Research, 472-475: 591-595. [doi:10.4028/www.scientific.net/AMR.472475.591]

Milašinović, D.D., 2003. Rheological-dynamical analogy: modeling of fatigue behavior. International Journal of Solids and Structures, 40(1):181-217. [doi:10.1016/ S0020-7683(02)00518-8]

Morel, F., 2001. A critical plane fatigue model applied to out-of-phase bending and torsion load conditions. 
Fatigue \& Fracture of Engineering Materials \& Structures, 24(3):153-164. [doi:10.1046/j.1460-2695.2001. 00390.x]

Mutoh, Y., Xu, J.Q., 2003. Fracture mechanics approach to fretting fatigue and problems to be solved. Tribology International, 36(2):99-107. [doi:10.1016/S0301-679X(02) 00136-6]

Peng, L.M., Fu, P.H., Li, Z.M., 2014. High cycle fatigue properties of cast $\mathrm{Mg}-x \mathrm{Nd}-0.2 \mathrm{Zn}-\mathrm{Zr}$ alloys. Journal of Materials Science, 49(20):7105-7115. [doi:10.1007/ s10853-014-8417-7]

Soppa, E.A., Kohler, C., Roos, E., 2014. Fatigue mechanisms in an austenitic steel under cyclic loading: experiments and atomistic simulations. Materials Science and Engineering A-Structural Materials Properties Microstructure and Processing, 597:128-138. [doi:10. 1016/j.msea.2013.12.036]

Stephens, R.I., Fuchs, H.O., 2001. Metal Fatigue in Engineering. Wiley, New York, p.59-122.

Verreman, Y., Guo, H., 2007. High-cycle fatigue mechanisms in 1045 steel under non-proportional axial-torsional loading. Fatigue and Fracture of Engineering Materials and Structures, 30(10):932-946. [doi:10.1111/j.14602695.2007.01164.x]

\section{中文概要}

题 目: 不同平均应力或应力比下 S-N 曲线之间的关系

目 的: 探讨平均应力或应力比对 S-N 曲线的影响, 并期 望得到不同应力比或平均应力下统一的 S-N曲线 的数学形式。

方 法: 1. 基于 Kachanov 的疲劳损伤演化律, 考虑循环 载荷作用下高周疲劳的实际情况, 提出疲劳损伤 演化模型；2. 采用高镇同（1981）的实验数据, 验证不同平均应力下 S-N 曲线的数学表达式; 3. 利用等效对称应力幅和等效对称寿命的概念, 研究不同平均应力下的 S-N 曲线数学表达式。

结 论：1. 提出任意循环比或平均应力下 S-N 曲线的统一 数学表达式; 2. 给出疲劳极限、比例系数和平均 应力间的关系; 3. 引入等效对称循环应力和寿命 的概念, 可以将任意循环比或平均应力下的疲劳 等效为对称疲劳。

关键词：损伤力学; S-N 曲线; 演化律; 等效方法; 疲劳 极限 